Recebido em 21/08/2017. Aprovado em 16/02/2018. Avaliado pelo sistema double blind peer review. Publicado conforme normas da ABNT.

http://dx.doi.org/10.22279/navus.2018.v8n3.p37-52.601

\title{
O teletrabalho na percepção dos teletrabalhadores e seus gestores: vantagens e desvantagens em um estudo de caso
}

\author{
Francieli Hau Graduada em Administração. Universidade Federal de Santa Catarina \\ (UFSC) - Brasil. haufrancieli@gmail.com \\ Marilda Todescat Doutora em Administração. Universidade Federal de Santa Catarina \\ (UFSC)-Brasil.marildat@gmail.com
}

\section{RESUMO}

Este trabalho aborda um tema proveniente das transformações nos ambientes organizacionais impulsionadas pela globalização e pelo avanço das tecnologias da informação e comunicação, o teletrabalho. O presente estudo busca analisar a implantação do teletrabalho em uma organização com jurisdição estadual de acordo com a percepção dos teletrabalhadores e seus gestores, no que se refere ao perfil dos sujeitos, motivações para ingresso na modalidade e as vantagens e desvantagens na percepção dos teletrabalhadores e seus gestores. Para isso, utilizou-se como procedimentos metodológicos a abordagem qualitativa, a estratégia de estudo de caso e também o estudo longitudinal dividido em duas coletas de dados, realizadas através de questionários contemplando a turma ingressante por meio do edital 2/2016. As informações obtidas derivam de respostas de 34 teletrabalhadores na primeira coleta e 26 na segunda coleta de um universo de 45 participantes. Os principais resultados referem-se ao perfil dos optantes pelo teletrabalho, em sua maioria são mulheres, casadas e com filhos. A principal motivação apontada para a escolha dessa modalidade de trabalho deu-se pela facilidade de conciliar a vida profissional com a vida familiar. O perfil de personalidade apontou como principais características capacidade de conciliar a vida profissional e familiar no mesmo espaço, facilidade de concentração. Em relação as principais vantagens do teletrabalho foram elencadas qualidade de vida em família e maior opção de organizar o tempo livre. Quanto as principais vantagens na percepção dos gestores, apontase a maior produtividade e motivação dos teletrabalhadores. A análise dos dados também permitiu concluir que o programa não possui grandes desvantagens na percepção dos sujeitos, sendo citados por uma pequena parcela de teletrabalhadores apenas visão preconceituosa em relação ao teletrabalho e as oportunidades de carreira reduzida, na percepção dos gestores, a falta de legislação específica e vulnerabilidade de dados e recursos.

Palavras-chave: Teletrabalho. Teletrabalhadores. Vantagens. Desvantagens.

\section{Teleworking in the perception of teleworkers and their managers: advantages and disadvantages in a case study}

\begin{abstract}
This research addresses a theme in global communication projects and information and communication technologies: telecommuting. It analyzes the implementation of teleworking in an organization under state jurisdiction, according to the perception of teleworkers and their managers, in what concerns the profile of the subjects, motivations for entry into this modality of work, its advantages and disadvantages. For this purpose, a case study, the qualitative approach, and a longitudinal study divided into two data collections, using questionnaires contemplating the entering group through the 2/2016 edict, were used as a methodological procedure. The information was obtained from the responses of 34 teleworkers in the first collection and 26 in the second collection of a universe of 45 participants. The main results refer to the profile of those who chose to telework: the majority is formed by women, married and with children. A major motivation for such a choice of work modality is the ease of conciliating work and family life. The personality profile pointed out as main characteristics the ability to reconcile professional and personal life in the same space and the facility in concentrating. In relation to the main advantages of telework were the quality of life in the family and greater choice of organization of free time. As disadvantages teleworkers mentioned the biased view of telecommuting and reduction in career opportunities. Mangers mentioned the lack of specific regulations and vulnerability of data and resources.
\end{abstract}


Keywords: Telecommuting. Teleworkers. Advantages. Disadvantages. 1 INTRODUÇÃO

O surgimento e a constante evolução das tecnologias da informação e da comunicação, ao lado do surgimento de novos modelos organizacionais e gerenciais, trouxeram mudanças nas relações homem-trabalho que até algum tempo atrás eram inimagináveis. Este cenário em constante transformação exigiu que as organizações buscassem novas formas de adaptação a esta nova conjuntura fortemente ligada ao desenvolvimento tecnológico, tornando possível tanto para empresas como para os trabalhadores novas formas de execução de tarefas, na prestação de serviços e também nas próprias relações de emprego.

Essa nova conjuntura fundamentada nas tecnologias da informação e na globalização, fez surgir a "necessidade de uma redefinição do tempo e do espaço, tendo como resultado novos processos na organização e no desenvolvimento do trabalho em si" (ESTRADA, 2014, p. 25). Surgiu, portanto, uma alternativa ao trabalho tradicionalmente realizado de forma presencial dentro das instalações das organizações, possibilitando às empresas e aos trabalhadores - apesar da distância física entre eles - estar em contato para realização do trabalho.

Dessa maneira surge o tema teletrabalho, que de acordo com Estrada (2014, p. 15.) pode ser definido como aquele "realizado com ou sem subordinação, usando antigas tecnologias de telecomunicação em virtude de uma relação de trabalho, permitindo a sua execução à distância, prescindindo da presença física do trabalhador em local específico de trabalho". Neste sentido, é oferecida ao teletrabalhador a oportunidade de gerenciar seu tempo e escolher a melhor maneira de realizar suas atividades e, desta forma, obter uma melhor qualidade de vida, satisfação profissional, aumento de produtividade entre outros benefícios. De forma similar, as organizações também podem reduzir custos, otimizar o tempo, melhorar a qualidade de vida dos colaboradores, aumentar a produtividade estando preparadas para acompanhar as transformações geradas pelas tecnologias da informação e comunicação. Ao encontro do exposto, a sociedade e o governo também obtêm vantagens quando o assunto é teletrabalho, como por exemplo, diminuição dos congestionamentos, do consumo de energia e da poluição.

Tantas vantagens para ambos os lados da relação de trabalho vêm acompanhadas de alguns entraves. O teletrabalho também tem seus pontos negativos, entre eles o isolamento social, dificuldade de equilibrar o trabalho e a vida pessoal, necessidade de organização e autodisciplina. Já para a empresa, pode-se citar a falta de uma regulamentação, a necessidade de tecnologias específicas e a vulnerabilidade dos dados e recursos da organização.

No Brasil esta modalidade começa a ser reconhecida e aceita através do Projeto 4.505/08 e, posteriormente, na Lei 12.551 de 15 de dezembro de 2011, que alterou o artigo $6^{\circ}$ das Consolidações das Leis do Trabalho (CLT), promovendo o reconhecimento dessa modalidade de trabalho executado no domicílio do empregado ou realizado a distância e equiparando ao trabalho realizado nas instalações do empregador, desde que estejam caracterizados os vínculos empregatícios. Porém no Brasil ainda não existe regulamentação específica para o teletrabalho, deixando uma lacuna em aberto com relação a esta modalidade.

Segundo Schmidt (2016) tanto organizações privadas como as públicas estão aderindo ao teletrabalho. Percebe-se que teletrabalho se tornará uma tendência e segundo Estrada (2014 p. 26), "esta forma de trabalho seria a mais conveniente para as exigências da globalização".

Dessa forma, o presente estudo objetiva responder à seguinte pergunta de pesquisa: qual a percepção dos teletrabalhadores e seus respectivos gestores, com relação à implantação do teletrabalho em uma organização pública com jurisdição estadual?

Acredita-se que o tema é relevante visto que possui poucos estudos na esfera pública que busquem identificar as vantagens e desvantagens encontradas pelos teletrabalhadores e também que busquem analisar os fatores que levam os trabalhadores a optarem pelo teletrabalho. Percebe-se um número relevante de trabalhos com um enfoque jurídico e concentrando a análise em torno da regulamentação do teletrabalho, acredita-se que este fato se deve ao teletrabalho não possuir uma legislação específica neste país. Nota-se que o maior número de trabalhos publicados sobre o tema está na área de administração, porém poucos abordam a questão das vantagens e desvantagens e a motivação que leva os teletrabalhadores a ingressarem nesta 
modalidade. De maneira mais específica, não foi encontrado nenhum trabalho na esfera pública com o foco pretendido neste trabalho nas bases de dados SCIELO, CAPES e IBITC.

A pesquisa foi realizada nesta organização, por se tratar de organização com jurisdição estadual e sua recente implantação da modalidade de teletrabalho devido ao avanço do processo eletrônico. Outro ponto de destaque foi a viabilidade de acesso aos teletrabalhadores e aos gestores, devido ao fato da pesquisadora atuar da área de Gestão de Pessoas da organização, área responsável pela implantação do projeto. Quanto à oportunidade, a presente pesquisa foi oportuna por ser realizada exatamente no início da implantação do teletrabalho, possibilitando a realização de um estudo longitudinal em duas coletas de dados.

\subsection{Objetivo geral}

Com o intuito de responder à questão de pesquisa, foi estabelecido o seguinte objetivo geral: Analisar a implantação do programa de teletrabalho, em uma organização pública com jurisdição estadual, na percepção dos teletrabalhadores e seus gestores.

\subsection{Objetivos específicos}

a) Identificar o perfil dos teletrabalhadores

b) Identificar a motivação dos teletrabalhadores com relação ao ingresso no teletrabalho

c) Descrever as vantagens e desvantagens do teletrabalho na percepção dos teletrabalhadores e dos respectivos gestores

\section{FUNDAMENTAÇÃO TEÓRICA}

A fundamentação teórica tem como objetivo a busca por teorias que dizem respeito ao estudo que está sendo abordado, para posterior análise e entrelaçamento de dados.

\subsection{A Sociedade da Informação}

A origem do atual cenário mundial se deu nos últimos trinta anos do século XVIII, na chamada primeira Revolução Industrial, quando surgiram as novas tecnologias como a máquina a vapor e de forma geral, a substituição das ferramentas manuais pelas máquinas (CASTELLS, 2007; TOFFLER, 2002; LOJKINE, 2002). Aproximadamente 100 anos depois com a segunda Revolução Industrial, ocorreu o desenvolvimento da eletricidade, do motor de combustão interna, dos produtos químicos com base científica e o início das tecnologias de comunicação, com a difusão do telégrafo e invenção do telefone (CASTELLS, 2007). Ainda para o autor, essas duas ondas têm importância crucial no que se refere ao conhecimento científico, difundindo-se por todo o sistema econômico e social, e que sustentou o desenvolvimento tecnológico dos próximos anos:

No fim do segundo milênio da Era Cristã, [...] uma revolução tecnológica concentrada nas tecnologias da informação começou a remodelar a base material da sociedade em ritmo acelerado. [...] As redes interativas de computadores estão crescendo exponencialmente, criando novas formas e canais de comunicação, moldando a vida e, ao mesmo tempo sendo moldadas por ela (CASTELLS, 2007, p. 39).

Para o autor, "a tecnologia é a sociedade, e a sociedade não pode ser entendida ou representada sem suas ferramentas tecnológicas" (CASTELLS, 2007, p. 43). Segundo o autor, apesar de indícios das tecnologias da informação serem encontrados antes da década de 1940, de fato só na década de 70 as novas tecnologias da informação foram difundidas; pode-se descrever três estágios que construíram a história das tecnologias baseadas em eletrônica: microeletrônica, computadores e telecomunicações. Os dois primeiros estágios foram responsáveis pela criação de dispositivos microeletrônicos e aumento da capacidade de computação, enquanto o último criou e desenvolveu os computadores em rede (TOFFLER 2002). 
Ainda nesta linha, Castells (2007 p. 82) cita que esses avanços ampliaram os efeitos das tecnologias da informação e comunicação (TICs), levando a criação da Internet, "talvez o mais revolucionário meio tecnológico da Era da Informação", que trouxe consigo os navegadores, onde o mundo inteiro foi integrado, criando uma "teia mundial". Corroborando, Zuffo (2004) afirma que o desenvolvimento dessas tecnologias, possibilitará um adensamento do que ele chama de "teia de comunicações" em nível mundial, que interligará pessoas e outros seres vivos, equipamentos e objetos.

Castells (2007, p. 119) afirma que "a informação e conhecimento sempre foram elementos cruciais no crescimento da economia, e a evolução da tecnologia determinou em grande parte a capacidade produtiva [...] e os padrões de vida, bem como formas sociais de organização econômica". Nesse sentido, o autor correlaciona os processos de trabalho com a evolução tecnológica:

O processo de trabalho situa-se no cerne da estrutura social. A transformação tecnológica e administrativa do trabalho e das relações produtivas dentro e em torno da empresa emergente em rede é o principal instrumento por meio do qual o paradigma informacional e o processo de globalização afetam a sociedade em geral (CASTELLS, 2007, p. 265).

Novos aspectos relacionados a flexibilidade fundamentam as transformações dos processos de trabalho, motivados pela concorrência e impulsionadas pela tecnologia. Carnoy (2000 apud CASTELLS, 2007) cita 4 elementos dessa transformação no surgimento de padrões flexíveis de trabalho:

a) Jornada de trabalho flexível: diferente do modelo tradicional 35-40 horas em expediente integral;

b) Estabilidade no emprego: regido por tarefas e não possui compromisso com permanência futura no emprego;

c) Localização: local de trabalho não se limita ao espaço físico da empresa durante parte do expediente ou durante todo o expediente;

d) Contrato social entre patrão e empregado: baseado no compromisso com direitos e deveres bem definidos por ambas as partes.

Para Castells (2007), a flexibilidade organizacional instituída pela Infoera criou a necessidade de trabalhadores ativos e de jornada flexível, bem como uma nova reestruturação dos sistemas de trabalho, levando a descentralização e a individualização destes. Para o autor, a forma tradicional de trabalho baseada no emprego com horário integral e projetos de carreira ao longo da vida estão deixando de existir de forma lenta, porém indiscutível, a tecnologia transforma profundamente a natureza do trabalho e a organização da produção, nesse sentido, uma nova reestruturação das organizações está gerando uma transformação no processo de trabalho, a sua individualização. Nesse cenário a ampliação do teletrabalho se faz sentir com maior intensidade.

\subsection{Teletrabalho}

Não há uma concordância entre os diversos autores quanto ao surgimento do teletrabalho, mas assevera-se que este tornou-se mais difundido a partir da ampliação do surgimento e uso das TICs. Outra dificuldade reside na definição de teletrabalho, devido ao "perfil multifacetado e à multiplicidade de situações que a prática o envolve" (COSTA, 2003, p. 11). Pinel (2012) corrobora com esta afirmação ao falar que as definições são variadas e se encontram em processo de evolução, não existindo um consenso por parte dos estudiosos do assunto, no que se refere a um conceito preciso.

A despeito dessa dificuldade para a Organização Internacional do Trabalho (OIT) teletrabalho é "a forma de trabalho efetuada em lugar distante do escritório central e/ou do centro de produção, que permita a separação física e que implique o uso de uma nova tecnologia facilitadora da comunicação" (OIT, 2010 apud PINEL, 2012).

Conforme a Carta Europeia para o Teletrabalho, este é um novo modo de organização do trabalho, que tem o potencial de contribuir à melhora da qualidade de vida, a práticas de trabalho sustentáveis e à igualdade participação dos cidadãos, sendo tal atividade um componente-chave da Sociedade da Informação. 
Estrada (2014) coloca a seguinte definição para o teletrabalho:

É aquele realizado com ou sem subordinação através do uso de antigas e novas formas de telecomunicação em virtude de uma relação de trabalho, permitindo à sua execução à distância, prescindindo da presença física do trabalhador em lugar específico de trabalho (ESTRADA, 2014 p.15).

Da mesma forma, diversos autores discutem sobre as vantagens e desvantagens sob diferentes perspectivas: da organização, do teletrabalhador e da sociedade. Na sequência, apresenta-se o Quadro 1, síntese dessas diferentes visões.

Quadro 1 - Vantagens e desvantagens do teletrabalho

\begin{tabular}{|c|c|c|}
\hline & Vantagens & Desvantagens \\
\hline \multirow{14}{*}{ 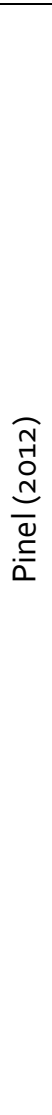 } & Teletrabalhador & Teletrabalhador \\
\hline & aumento da produtividade; & isolamento social; \\
\hline & $\begin{array}{l}\text { redução de custos com alimentação, vestuário e } \\
\text { deslocamento; }\end{array}$ & oportunidades de carreira reduzidas; \\
\hline & $\begin{array}{l}\text { diminuição do stress causado em } \\
\text { deslocamento; }\end{array}$ & $\begin{array}{l}\text { aumento dos custos relacionados ao trabalho } \\
\text { em casa; }\end{array}$ \\
\hline & ausência de competição e clima de competição; & $\begin{array}{l}\text { em caso de cortes, maior probabilidade de ser } \\
\text { demitido; }\end{array}$ \\
\hline & autonomia, próprio ritmo do trabalhador; & $\begin{array}{l}\text { falta de lei específica para tratar a relação } \\
\text { complexa do teletrabalho. }\end{array}$ \\
\hline & menor número de interrupções; & \\
\hline & maior capacidade de concentração; & \\
\hline & $\begin{array}{l}\text { maior autonomia e independência devido à } \\
\text { menor pressão durante o desenvolvimento de } \\
\text { suas tarefas; }\end{array}$ & \\
\hline & maior flexibilidade na escolha de sua residência, & \\
\hline & melhoria da qualidade de vida em família; & \\
\hline & maior opção de organizar o tempo livre; & \\
\hline & $\begin{array}{l}\text { retorno mais rápido depois de uma licença } \\
\text { médica; }\end{array}$ & \\
\hline & $\begin{array}{l}\text { no caso de um portador de deficiências físicas, } \\
\text { diminui a dificuldade de deslocamento. }\end{array}$ & \\
\hline \multirow{8}{*}{ 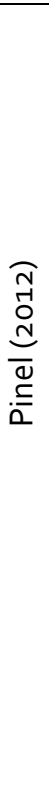 } & $\underline{\text { Organização }}$ & $\underline{\text { Organização }}$ \\
\hline & redução de custos imobiliário e pessoal; & falta de lealdade para com a empresa; \\
\hline & diminuição do absenteísmo; & objeções por parte de alguns sindicatos; \\
\hline & maior alcance na seleção de teletrabalhadores; & $\begin{array}{l}\text { aumento de vulnerabilidade de dados e } \\
\text { recursos; }\end{array}$ \\
\hline & oportunidade da empresa operar 24 horas; & $\begin{array}{l}\text { aumento de custos a curto prazo, em relação } \\
\text { à infraestrutura necessária de uma } \\
\text { administração e execução de tarefas } \\
\text { remotas; }\end{array}$ \\
\hline & $\begin{array}{l}\text { em caso de catástrofes atividades não são } \\
\text { suspensas; }\end{array}$ & falta de leis específicas sobre o teletrabalho; \\
\hline & maior agilidade e flexibilidade para a empresa; & $\begin{array}{l}\text { contratos diversificados de trabalhos para } \\
\text { administrar; }\end{array}$ \\
\hline & menor rotatividade de pessoal. & $\begin{array}{l}\text { o desenvolvimento do trabalho é fortemente } \\
\text { dependente de tecnologia. }\end{array}$ \\
\hline
\end{tabular}









\begin{tabular}{|c|c|c|}
\hline & $\begin{array}{l}\text { - maior quantidade de empregos em zonas } \\
\text { rurais; }\end{array}$ & \\
\hline & $\begin{array}{l}\text { - melhor organização do território e } \\
\text { desenvolvimento regional. }\end{array}$ & \\
\hline \multirow{11}{*}{ 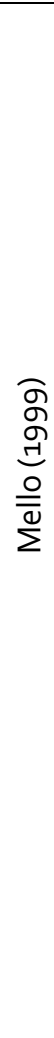 } & Teletrabalhador: & Teletrabalhador: \\
\hline & ambiente de trabalho flexível; & visão preconceituosa; \\
\hline & maior produtividade; & isolamento social; \\
\hline & $\begin{array}{l}\text { menos estresse provocado pelo } \\
\text { congestionamento no trânsito, pelas relações } \\
\text { conflitantes no trabalho; }\end{array}$ & $\begin{array}{l}\text { distração com os membros familiares e } \\
\text { invasão do espaço profissional; }\end{array}$ \\
\hline & mais tempo com a família e dedicação ao lazer. & $\begin{array}{l}\text { gerenciamento falho do tempo em virtude da } \\
\text { desatenção e desorganização de horários de } \\
\text { trabalho. }\end{array}$ \\
\hline & Organização: & \\
\hline & redução de custos de infraestrutura; & \\
\hline & aumento de produtividade; & \\
\hline & $\begin{array}{l}\text { pode-se recrutar funcionários a partir de uma } \\
\text { área geográfica maior; }\end{array}$ & \\
\hline & $\begin{array}{l}\text { menor rotatividade de funcionários talentosos } \\
\text { que por alguma razão necessitam mudar de } \\
\text { local; }\end{array}$ & \\
\hline & eliminação do absenteísmo. & \\
\hline
\end{tabular}

Fonte: Elaborado pelas autoras (2016).

\section{PROCEDIMENTOS METOdOLÓGICOS}

Quanto à abordagem da pesquisa, foi utilizada a abordagem qualitativa. Quanto aos objetivos, a pesquisa classifica-se como descritiva. A pesquisa também pode ser classificada de acordo com a sua estratégia, assim, caracteriza-se como um estudo de caso, tendo sido realizada em um órgão público de abrangência estadual que lançou um edital possibilitando aos funcionários interessados, adotar o teletrabalho pelo período de um ano podendo ser renovado a critério do órgão.

Outro aspecto essencial a considerar é quanto ao tipo de estudo no tempo. Nesta pesquisa utilizou-se o estudo longitudinal, quando os mesmos sujeitos são estudados sobre um período determinado, neste caso específico, compreendendo a primeira coleta em março de 2016 e a segunda em setembro do mesmo ano.

Os sujeitos foram o coordenador do Programa, os gestores e os teletrabalhadores, estes últimos ingressantes por meio do edital 02/2016, que disponibilizou 50 vagas e teve 45 vagas preenchidas. Na primeira coleta obteve-se 34 respostas e na segunda coleta 26 respostas dos teletrabalhadores, com relação aos gestores foram obtidas 10 respostas da segunda coleta.

$\mathrm{Na}$ presente pesquisa foram utilizadas para a fundamentação teórica as técnicas de análise documental: documentos e normas internas da organização para descrever o projeto de teletrabalho; e também bibliográfica: livros, artigos, teses e dissertações. Dessa forma, para atender aos objetivos, prosseguiu-se com a coleta de dados, realizada através de pesquisa longitudinal em duas etapas, conforme Quadro 2. 


\begin{tabular}{|c|c|c|c|c|}
\hline & Objetivos & Sujeitos & Coleta de Dados & $\begin{array}{l}\text { Análise de } \\
\text { Dados }\end{array}$ \\
\hline \multirow[t]{2}{*}{$1^{\circ}$ coleta } & $\begin{array}{l}\text { Identificar o perfil dos } \\
\text { teletrabalhadores }\end{array}$ & Teletrabalhadores & $\begin{array}{l}\text { Questionário (questões } \\
\text { fechadas) }\end{array}$ & $\begin{array}{ll}\text { Tabulação } & \text { e } \\
\text { Interpretação } & \end{array}$ \\
\hline & $\begin{array}{l}\text { Identificar a motivação } \\
\text { dos teletrabalhadores }\end{array}$ & Teletrabalhadores & $\begin{array}{l}\text { Questionário (questão } \\
\text { aberta) }\end{array}$ & $\begin{array}{l}\text { Análise } \quad \mathrm{de} \\
\text { Conteúdo }\end{array}$ \\
\hline $\begin{array}{l}2^{\circ} \\
\text { coleta }\end{array}$ & $\begin{array}{l}\text { Identificar vantagens e } \\
\text { desvantagens }\end{array}$ & $\begin{array}{l}\text { Teletrabalhadores, } \\
\text { gestores e coordenador }\end{array}$ & $\begin{array}{l}\text { Questionários } \\
\text { (questões fechadas) e } \\
\text { entrevista } \\
\text { semiestruturada com o } \\
\text { coordenador do } \\
\text { Programa }\end{array}$ & $\begin{array}{ll}\text { Tabulação } & \mathrm{e} \\
\text { interpretação } & \end{array}$ \\
\hline
\end{tabular}

Fonte: Elaborado pelas autoras (2016).

A análise dos dados iniciou-se com a tabulação das respostas obtidas através dos questionários, com auxílio do programa Excel para facilitar a visualização dos resultados. O passo seguinte foi a análise das questões, onde utilizou-se a análise de conteúdo (BARDIN 2006). As categorias de análise foram construídas a partir do quadro 1, apresentado na fundamentação teórica.

A presente pesquisa limitou-se a investigar os objetivos definidos anteriormente somente com a turma ingressante do edital 02/2016, não podendo afirmar que os resultados obtidos sejam verificados em quaisquer outras turmas.

\section{ANÁLISE DOS RESULTADOS}

O primeiro objetivo da pesquisa consistiv em identificar o perfil dos respondentes quanto as seguintes informações: sexo, idade, escolaridade, estado civil, se possui filhos, tempo de trabalho no órgão, localidade onde mora e tempo para percorrer o trajeto do trabalho até a residência conforme descrito no Quadro 3.

Quadro 3-Perfil dos Respondentes

\begin{tabular}{|c|c|c|c|c|c|}
\hline \multirow{2}{*}{ Sexo } & Masculino & $24 \%$ & Estado & Solteiro & $23 \%$ \\
\hline & Feminino & $76 \%$ & Civil & Casado & $71 \%$ \\
\hline \multirow{4}{*}{ Idade } & De 27 a 33 anos & $23 \%$ & & Divorciado & $6 \%$ \\
\hline & De 34 a 40 anos & $50 \%$ & \multirow{2}{*}{$\begin{array}{l}\text { Tem } \\
\text { Filhos }\end{array}$} & Sim & $62 \%$ \\
\hline & De 41 a 47 anos & $12 \%$ & & Não & $38 \%$ \\
\hline & Mais de 48 anos & $15 \%$ & \multirow{3}{*}{$\begin{array}{l}\text { Tempo } \\
\text { de } \\
\text { trabalho } \\
\text { no órgão }\end{array}$} & Até 10 anos & $55 \%$ \\
\hline \multirow{3}{*}{ Escolaridade } & Pós-graduado & $53 \%$ & & De 10 a 20 anos & $36 \%$ \\
\hline & Graduado & $41 \%$ & & Mais de 20 anos & $9 \%$ \\
\hline & $\begin{array}{l}\text { Graduação } \\
\text { incompleta }\end{array}$ & $6 \%$ & \multirow{4}{*}{$\begin{array}{l}\text { Tempo } \\
\text { de trajeto } \\
\text { casa- } \\
\text { trabalho }\end{array}$} & Até $30 \mathrm{~min}$ & $64 \%$ \\
\hline \multirow{3}{*}{$\begin{array}{l}\text { Localidade } \\
\text { onde } \\
\text { trabalha }\end{array}$} & $\begin{array}{l}\text { Região } \\
\text { Metropolitana }\end{array}$ & $15 \%$ & & De 31 min a 1 hora & $21 \%$ \\
\hline & Capital & $23 \%$ & & Mais de 1 hora & $15 \%$ \\
\hline & Interior & $62 \%$ & & & \\
\hline \multirow{2}{*}{$\begin{array}{l}\text { Experiência } \\
\text { teletrabalho }\end{array}$} & Sim & $3 \%$ & & & \\
\hline & Não & $97 \%$ & & & \\
\hline
\end{tabular}

Fonte: Dados Primários (2016). 
Observa-se pelo quadro acima que o perfil preponderante é composto por mulheres casadas e com filhos, idade de 30 a 40 anos e alto nível de escolaridade, em sua maioria moram no interior do estado e não tinham experiência com o teletrabalho.

Para complementar o perfil dos respondentes ainda foi questionado o seu nível de satisfação referente aos aspectos pessoal e familiar com $85,5 \%$ afirmando estar satisfeito em oposição a $14,5 \%$ insatisfeitos; relacionamento interpessoal no trabalho $82 \%$ mostrou-se satisfeito em oposição a $18 \%$ insatisfeitos e, finalmente, sobre sua vida profissional $67 \%$ apresentou satisfação e $33 \%$ insatisfação. Tais números apontam que a adoção do teletrabalho não é uma opção de fuga por problemas em seu ambiente de trabalho.

Nilles (1999 apud SCHROEDER, 2007) entende que nem todas as pessoas, empregos ou trabalhos adaptam-se ao teletrabalho. $\mathrm{O}$ autor aponta que o perfil de personalidade deve possuir características como automotivação, autodisciplina, experiência e competência profissional, flexibilidade e espírito de inovação, capacidade de socialização, relação com a família que permita conciliação da vida profissional e familiar e, também, escolha do momento certo na vida e na carreira. Schroeder (2007) aponta, em contrapartida, que não devem optar pelo teletrabalho pessoas com necessidade supervisão física direta, com menor autoestima e disciplina, ou que necessitem de relações para não se sentirem isoladas. Essas categorias apontadas por Nilles (1999 apud SCHROEDER, 2007) e Mello (1999) deram origem ao gráfico 1 de perfil personalidade.

Para os autores acima citados, a família é um elemento importante a ser considerado, pois o teletrabalho não deve ser mero recurso para resolver problemas domésticos, nesse sentido, afirma que é necessário um ambiente adequado, com espaço claramente definido para o teletrabalho, havendo separação em relação às atividades familiares. Quando perguntados se: "Consigo administrar minhas relações familiares e profissionais no mesmo espaço?", 97,06\% indicaram que os teletrabalhadores conseguem administrar esta relação, não interferindo no desenvolvimento do trabalho.

A segunda afirmação com maior número de respostas positivas: "Tenho facilidade de concentração", totalizou 97,06\%. Essa afirmação reitera a anterior quando relacionada ao ambiente adequado e com espaço claramente definido para o teletrabalho, possibilitando uma maior concentração a fim de desenvolver o trabalho com qualidade. A terceira afirmação, também como número de respostas positivas de $97,06 \%$ é a seguinte: "Tenho facilidade de iniciar novas atividades", esta afirmação está relacionada à competência e preparação citada por Mello (1999).

A quarta e a quinta afirmação - "Automotivada" e "Autodisciplinada" - obtiveram $85,30 \%$ de respostas positivas. Devido às características desta modalidade é necessário que o teletrabalhador seja autodisciplinado para desenvolver seu trabalho, uma vez que está distante do ambiente físico da organização e da supervisão do gestor.

A sexta assertiva: "Tenho facilidade de realizar várias tarefas ao mesmo tempo" está relacionada à flexibilidade e espírito de inovação citada pelos dois autores. Para Mello (1999) esta característica remete a facilidade em se adaptar à novas situações, neste caso, situações que possam exigir mudanças e atualizações das atividades, requerendo do teletrabalhador esta flexibilidade e espírito de inovação já que este precisará se adequar e adaptar individualmente. Esta afirmação obteve $85,29 \%$ de respostas positivas, mostrando que a grande maioria possui essa característica.

A sétima característica: "Percebo oportunidade de crescimento/desenvolvimento no meu trabalho" obteve $67,65 \%$ de respostas positivas e $32,35 \%$ de respostas mostrando alguma insatisfação. Nota-se que uma parcela dos respondentes possui algum tipo de insatisfação com relação ao seu crescimento e desenvolvimento profissional.

Por fim, a última afirmação: "Prefiro trabalhar sozinho e não em grupo", 50\% dos teletrabalhadores optaram por respostas positivas e $50 \%$ discordaram, tal comportamento pode ser explicado pelos aspectos anteriores, a opção pelo teletrabalho não é, necessariamente, por insatisfação com seu ambiente de trabalho. 


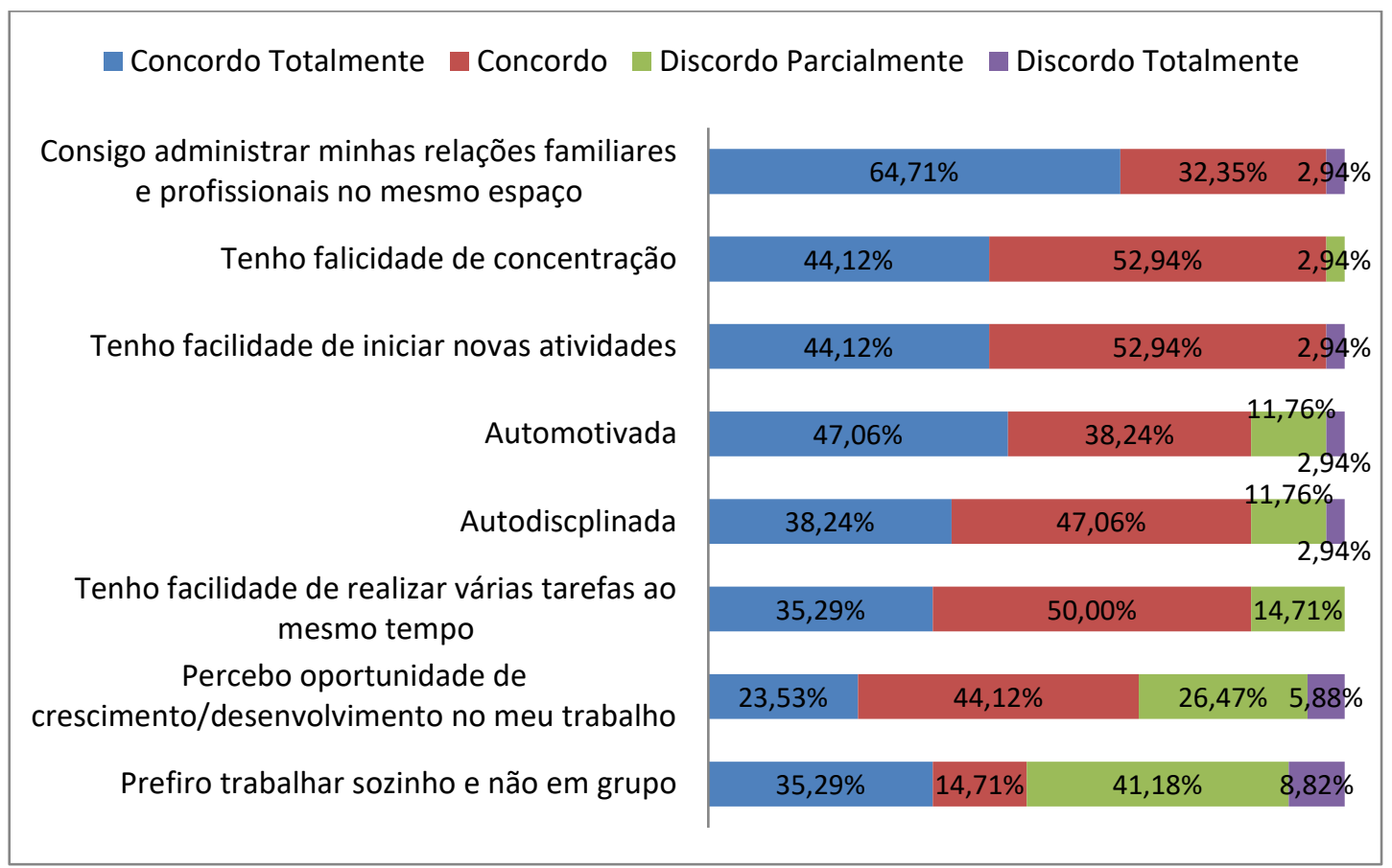

Fonte: Dados Primários, 2016.

O segundo objetivo buscou identificar a motivação dos teletrabalhadores com relação ao ingresso no teletrabalho. Para isso foi realizada, na primeira coleta, uma questão aberta para que os teletrabalhadores pudessem descrever sua motivação, a mesma questão foi repetida na segunda coleta, buscando analisar e comparar as respostas no início do programa e seis meses após o início. Por se tratar de questão aberta, trabalhou-se com a média de respostas.

Tabela 1 - Critérios de motivação teletrabalhadores

\begin{tabular}{lccc}
\multicolumn{1}{c}{ Critérios } & $\mathbf{1}^{\text {a }}$ coleta & $\mathbf{2}^{\text {a coleta }}$ & Diferença (\%) \\
Relação familiar & $33,33 \%$ & $31,58 \%$ & $1,75 \%$ \\
Deslocamento & $15,69 \%$ & $26,32 \%$ & $10,63 \%$ \\
Flexibilidade de horários & $13,73 \%$ & $10,53 \%$ & $3,20 \%$ \\
Problemas de saúde & $11,76 \%$ & $5,26 \%$ & $6,50 \%$ \\
Qualidade de vida & $5,88 \%$ & $7,89 \%$ & $2,01 \%$ \\
Desempenho/produtividade & $5,88 \%$ & $2,63 \%$ & $3,25 \%$ \\
Redução de custos & $3,92 \%$ & $5,26 \%$ & $1,34 \%$ \\
Outros & $9,80 \%$ & $10,53 \%$ & $0,72 \%$ \\
\hline Total & $100,00 \%$ & $100,00 \%$ & - \\
\hline
\end{tabular}

Fonte: Dados Primários (2016).

Observa-se que a relação familiar foi a grande motivadora para a mudança na opção da modalidade de trabalho, corroborando Nilles (1997 apud SCHROEDER, 2007) apontando como um dos principais motivos da escolha dessa modalidade o fato de que o teletrabalhador pode passar mais tempo com a família, pode aproveitar intervalos de trabalho com os filhos, esposa/ marido ou pais. Tal motivação é congruente com o perfil preponderante dos sujeitos pesquisados.

O terceiro objetivo buscou identificar as vantagens e desvantagens na percepção de seus praticantes e seus respectivos gestores. Para isso, foi realizado uma lista de assertivas a partir das categorias extraídas dos autores com uso de escala Likert, sendo 5 para a maior vantagem/desvantagem e 1 para a menor vantagem/desvantagem. 
As maiores vantagens elencadas pelos teletrabalhadores foram "qualidade de vida em família" e "maior organização do tempo livre", ambas com 76,92\%. Percebe-se que os teletrabalhadores acreditam que a maior vantagem seja a possibilidade de maior equilíbrio entre vida familiar e vida profissional, uma conciliação entre estas esferas, buscando maior proximidade da família. Da mesma forma, "uma maior organização do tempo livre" também obteve mesmo número de respostas, evidenciando que o teletrabalhador está buscando um maior equilíbrio entre a vida profissional e a vida pessoal e/ou familiar.

Na sequência, a vantagem "evitar estresse com deslocamento" aparece com 73,08\%. Rodrigues (2011) aponta que economizar tempo, deixar de sofrer com tensões e poluições no trânsito também são algumas das principais vantagens, impactando não somente na produtividade, mas também na diminuição do estresse.

A terceira vantagem refere-se a "maior concentração", com 65,38\%. Pinel (2012) vai ao encontro desta afirmação, quando afirma que a quantidade de interferências em casa é menor que no ambiente convencional de trabalho e, como consequência, possibilita uma maior concentração para realização do trabalho.

\section{Gráfico 2 - Vantagens na percepção dos teletrabalhadores}



Fonte: Dados Primários (2016).

Na sequência apresentam-se as desvantagens mais relevantes na percepção dos sujeitos da pesquisa. Nota-se de maneira geral que não há nenhuma grande desvantagem. A maior delas, com 38,46\% foi a visão preconceituosa com o teletrabalho. Mello (1999) cita esta questão como desvantagem uma vez que a sociedade, colegas de trabalho e até mesmo familiares não têm entendimento do assunto e acabam criando esta visão justamente pela falta de conhecimento. 
Em seguida, a desvantagem citada com $26,96 \%$ é o afastamento do campo profissional e oportunidade de carreira reduzida. Para Rodrigues (2011) o distanciamento e perda de contato nas relações de trabalho podem impedir, em muitos casos, a ascensão profissional e promoções. Constatou-se certa preocupação dos teletrabalhadores em relação a este aspecto.

Mais trabalho devido ao aumento de produtividade exigida formalmente do teletrabalhador é apontada como terceira maior desvantagem. De acordo com a Resolução que normatiza a modalidade, o teletrabalhador deve produzir 20\% a mais do que os servidores presenciais, diante disso $23,08 \%$ dos teletrabalhadores aponta esse aumento de produtividade como uma desvantagem do teletrabalho.

Gráfico 3-Desvantagens na percepção dos teletrabalhadores

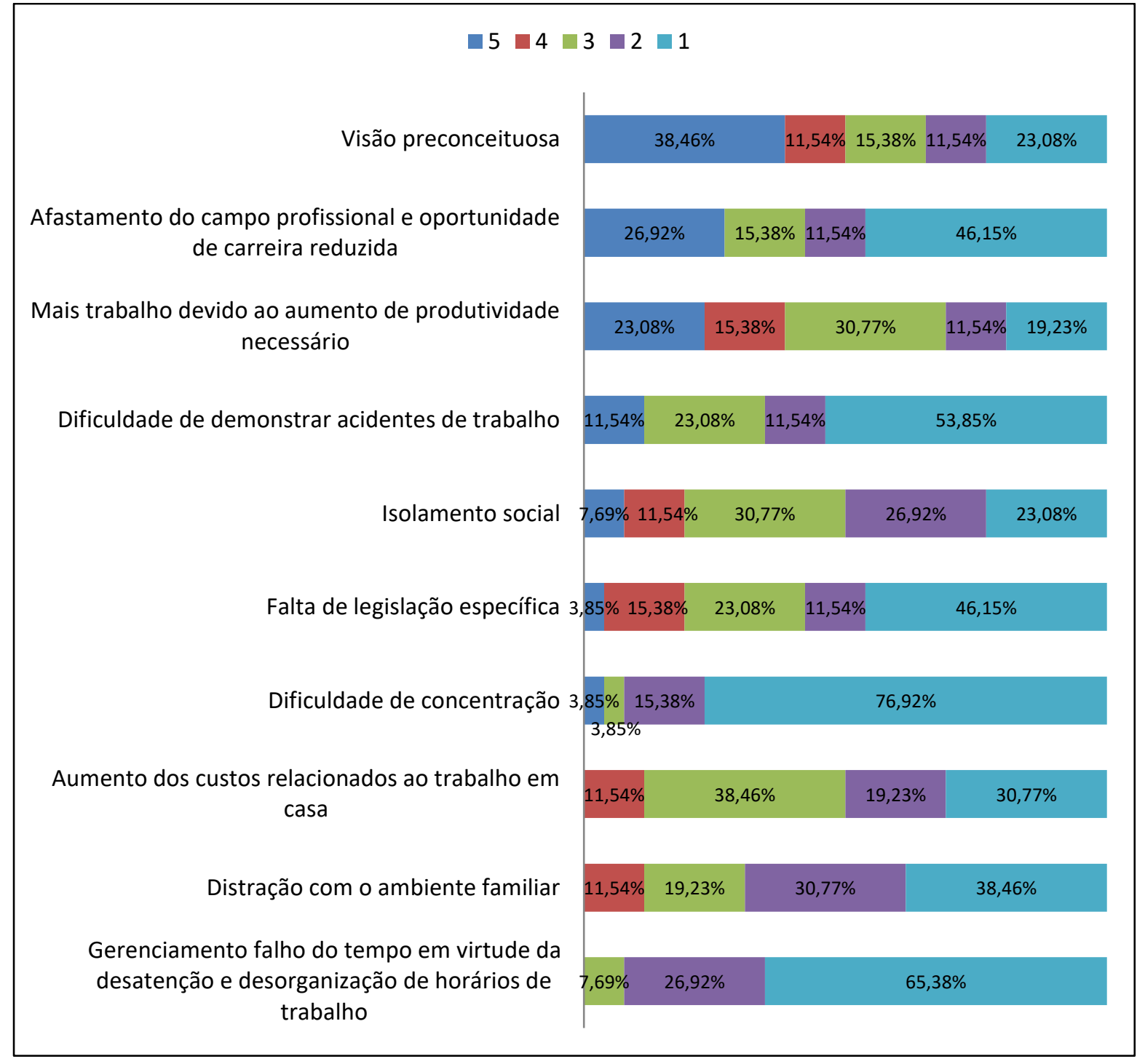

Fonte: Dados Primários (2016).

Tal pergunta também foi feita aos gestores, de acordo com o gráfico 4, maior motivação e aumento de produtividade dos teletrabalhadores aparecem como maiores vantagens obtendo $70 \%$ das respostas. Como o aumento de produtividade é um requisito para ingresso na modalidade, acredita-se que a visão dos gestores reafirma esta vantagem para a organização. Com relação à outra vantagem, também com 70\%, percebe-se a preocupação dos gestores com a motivação de seus subordinados, vantagem essa que tem impacto direto na produtividade.

Em seguida está a diminuição do absenteísmo e/ou rotatividade, pois como citado por Pinel (2012), a grande variedade de doenças e outros impedimentos físicos são suficientemente graves para impedir o 
teletrabalhador de ir ao escritório, mas não tão graves que não possa trabalhar em casa, nesse sentido, a rotatividade também tende a ser menor. Esta vantagem obteve $50 \%$ das respostas.

Com menores percentuais estão a redução de custos com infraestrutura e maior alcance na seleção de teletrabalhadores, com 30\% e 20\%, respectivamente. A redução de custos aparece como incentivo no sentido de diminuir os custos com espaço, estacionamento, equipamentos, energia elétrica, entre outros específicos. Já o maior alcance na seleção dos teletrabalhadores relaciona-se com a busca e também em como manter funcionários mais qualificados e com maior produtividade.

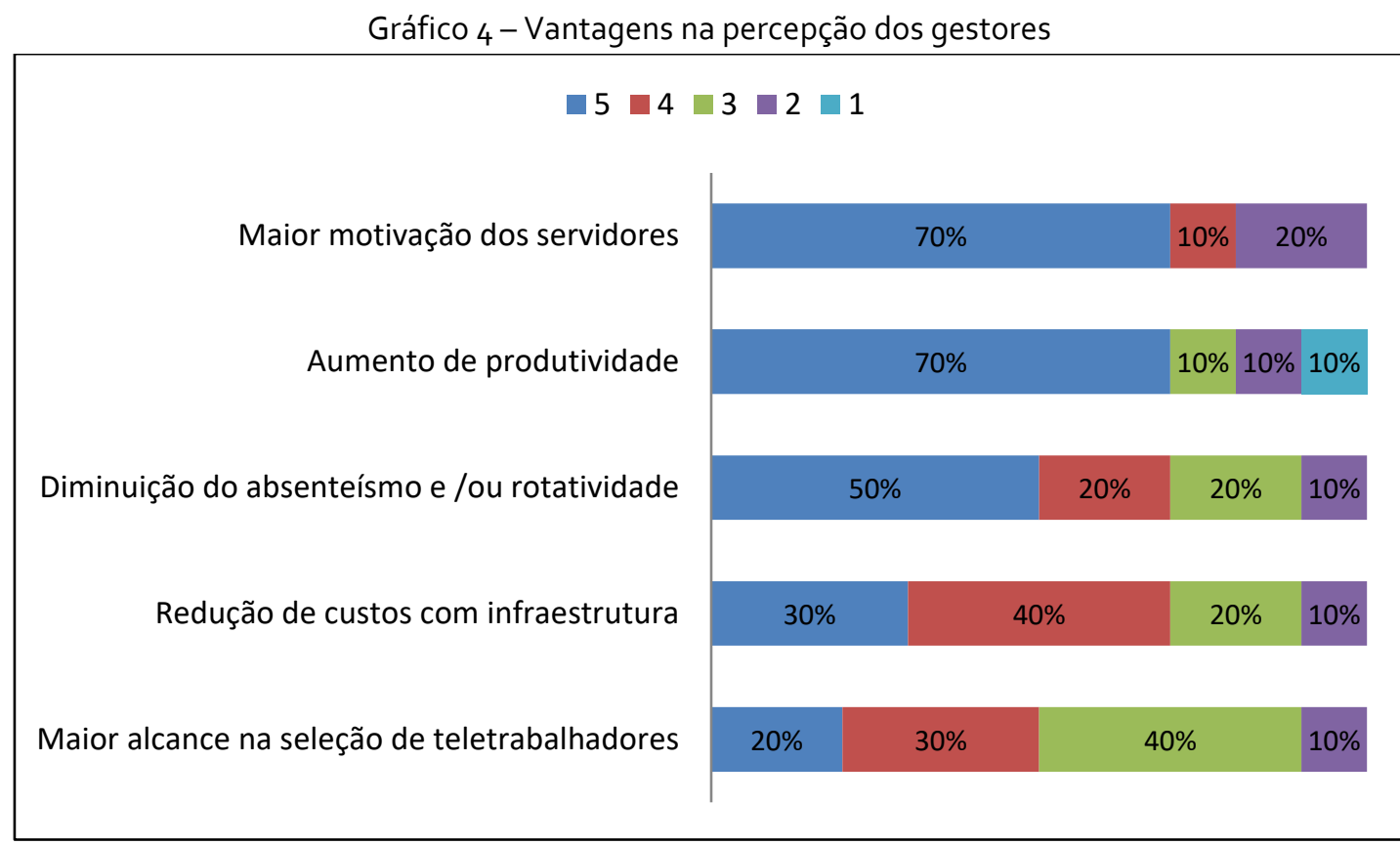

Fonte: Dados Primários (2016)

Com relação às desvantagens (Gráfico 5), ocorre o mesmo para os gestores, estes não percebem grandes desvantagens para a organização, apontando apenas falta de legislação específica e vulnerabilidade de dados e recursos, ambas, com 20\%. Pinel (2012) cita o fato de que o desenvolvimento do trabalho ser totalmente dependente da tecnologia pode gerar maior risco quanto à segurança dos dados. A autora aponta também outra desvantagem, que pode ser tanto para os teletrabalhadores como para as organizações, a falta de uma legislação completa e específica que regulamente esta relação de trabalho, abrangendo direitos e deveres específicos incidentes.

Observa-se que as desvantagens com menor impacto para a organização na percepção dos gestores são a objeção por parte dos sindicatos e o aumento de custos/investimentos de curto prazo. Nota-se que no caso específico desta organização estas desvantagens não necessitam de atenção de acordo com a opinião dos gestores. 
Gráfico 5 - Desvantagens na percepção dos gestores

\begin{tabular}{|c|c|c|c|c|}
\hline \multirow{2}{*}{ Falta de legislação específica } & \multicolumn{3}{|c|}{$\square=2 \square 1$} & \multirow[b]{2}{*}{$30 \%$} \\
\hline & $20 \%$ & $20 \%$ & $30 \%$ & \\
\hline \multirow{2}{*}{$\begin{array}{l}\text { Vulnerabilidade de dados e recursos } \\
\text { Contratos diversificados de trabalhos para } \\
\text { administrar }\end{array}$} & $20 \%$ & $20 \%$ & $20 \%$ & $40 \%$ \\
\hline & \multicolumn{2}{|l|}{$30 \%$} & $40 \%$ & $30 \%$ \\
\hline Objeções por parte de sindicatos & $20 \%$ & $20 \%$ & & $60 \%$ \\
\hline $\begin{array}{l}\text { Aumento de custos/investimentos a curto } \\
\text { prazo }\end{array}$ & $10 \%$ & $40 \%$ & \multicolumn{2}{|r|}{$50 \%$} \\
\hline
\end{tabular}

Fonte: elaborada pelas autoras (2016).

\section{CONCLUSÃO}

A pesquisa teve como objetivo analisar a implantação do Programa de teletrabalho em um órgão de abrangência estadual na percepção dos teletrabalhadores e seus gestores. Como resposta ao primeiro objetivo, a descrição do perfil dos teletrabalhadores, obteve-se as seguintes informações: $76 \%$ são do sexo feminino, $71 \%$ é casado/união estável, $94 \%$ com no mínimo superior completo e $62 \%$ tem filhos. Observou-se que a maioria dos respondentes está satisfeita nas áreas pessoal e familiar, relacionamento interpessoal no trabalho e vida profissional. Diante das respostas percebeu-se também que estão preparados para desenvolver seu trabalho distante do ambiente organizacional.

O segundo objetivo foi alcançado expondo-se as motivações para ingresso no teletrabalho, notou-se que a segunda coleta apenas reafirmou as principais motivações já citadas na primeira, nesta ordem, relação familiar, deslocamento e flexibilidade. Um dado que vai ao encontro da principal motivação é a principal característica do perfil de personalidade, "consigo administrar minhas relações familiares e profissionais no mesmo espaço". Percebeu-se também uma característica relevante, $76 \%$ dos respondentes é do sexo feminino e $57,69 \%$ dessas mulheres relacionaram sua motivação para ingresso no teletrabalho à melhoria da qualidade de vida em família, com os filhos e/ou marido.

No que se refere ao terceiro objetivo, as maiores vantagens elencadas pelos teletrabalhadores foram qualidade de vida em família e maior organização do tempo livre, evidenciando que o teletrabalhador está buscando um maior equilíbrio entre a vida profissional e a vida pessoal e/ou familiar. Observa-se uma correlação direta entre esta vantagem com a principal motivação que é a busca de maior equilíbrio entre vida familiar/pessoal e vida profissional. A segunda maior vantagem para o teletrabalhador é evitar estresse com deslocamento, tal vantagem vai totalmente ao encontro da segunda motivação apontada, não despender tempo com deslocamento.

Notou-se que o teletrabalhador não apontou nenhuma grande desvantagem, além da visão preconceituosa, seguida do afastamento do campo profissional e oportunidade de carreira reduzida, porém quando comparadas as desvantagens com as características de perfil observou-se que um número relevante de respondentes apontou como negativa a questão: "Percebo oportunidade de crescimento/desenvolvimento no meu trabalho", tal congruência de respostas aponta certa preocupação dos teletrabalhadores em relação ao aspecto de progressão em sua carreira.

De acordo com a percepção dos gestores, a maior motivação e aumento de produtividade dos teletrabalhadores aparecem como maiores vantagens. Com relação às desvantagens, ocorre o mesmo para os gestores, estes não percebem grandes desvantagens para a organização, apontando apenas falta de legislação 
específica e vulnerabilidade de dados e recursos, ambas, com apenas 20\%. Ressalta-se que na época de realização desta pesquisa no ano de 2016, ainda não havia qualquer discussão sobre a reforma trabalhista discutida atualmente que aborda tal lacuna, contudo a despeito das discussões atuais ainda nenhuma mudança concreta na legislação foi apontada. Na percepção do coordenador do programa, as principais vantagens são a produtividade, maior qualidade nos serviços e a diminuição do absenteísmo.

Em suma, nota-se que os respondentes percebem mais vantagens que desvantagens no teletrabalho, portanto teletrabalhadores e a instituição têm a ganhar com a implantação de um Programa desta abrangência, porém são necessários alguns ajustes para que a modalidade opere em sua melhor configuração, buscando a melhoria contínua da sua gestão. Observa-se que são muitos os desafios, como a falta de legislação específica, formalização da modalidade e também a adaptação cultural. Concluiu-se que os gestores têm papel fundamental no que se refere às formas de comunicação e ao feedback, dessa forma, devem priorizar métodos de interação eficazes no ambiente virtual. Também é necessário que a organização adote uma postura de maior clareza sobre as metas e exigências do programa para os servidores presenciais e gestores, e dessa forma gerar uma maior confiança entre todas estas partes em relação ao teletrabalho. Por fim, devido à ausência de contato presencial é importante que a organização utilize ferramentas para compartilhamento de conhecimento, interação e até mesmo que estimulem a criação de um ambiente social.

Apesar dos dados apontarem um número expressivo de teletrabalhadores a nível nacional, a modalidade ainda é considerada incipiente no país, principalmente na esfera pública. Abrem-se assim, oportunidades para possíveis estudos futuros sobre o tema. Como sugestão indica-se áreas que poderiam contribuir para o enriquecimento da literatura sobre o teletrabalho, voltados às singularidades do país. $\mathrm{O}$ primeiro refere-se a estudos comparativos entre as motivações na esfera pública e privada e suas implicações no trabalho e na vida familiar, pessoal e profissional do teletrabalhador. O segundo refere-se a uma questão de destaque encontrada nesta pesquisa, a adoção do teletrabalho na área pública em sua maioria por mulheres, um estudo mais aprofundando sobre como as características dos gêneros pode influenciar a adoção a modalidade.

\section{REFERENNCIAS}

BARDIN, L. Análise de conteúdo. Lisboa: Edições 70, 2006.

BRASIL. Lei 12.551, de 16 de dezembro de 2011. Altera o art. 6으 da Consolidação das Leis do Trabalho (CLT), aprovada pelo Decreto-Lei no 5.452, de 1o de maio de 1943, para equiparar os efeitos jurídicos da subordinação exercida por meios telemáticos e informatizados à exercida por meios pessoais e diretos. [2011]. Disponível em: <http://www.planalto.gov.br/ccivil_03/_ato2011-2014/2011/lei/l12551.htm >. Acesso em: 21 maio 2016.

CASTELLS, Manuel. A Sociedade em Rede. 10. ed. São Paulo: Paz e Terra, 2007.

COSTA, I. S. A. Poder/saber e subjetividade na construção do sentido do teletrabalho.2003. Tese (Doutorado em Administração Pública de Empresas) - Fundação Getúlio Vargas (FGV), Rio de Janeiro, 2003.

ESTRADA, Manuel Martin Pino. Teletrabalho\& Direito: o trabalho a distância e sua análise jurídica em face aos avanços tecnológicos. Curitiba: Juruá, 2014. 188 p.

GAMARSKI, Rachel. Brasileiros desejam mais flexibilidade no trabalho, diz CNI. 2015.Disponível em: <http://www.sobratt.org.br/index.php/29032016-brasileiros-desejam-mais-flexibilidade-no-trabalho-diz-cni/>. Acesso em: 25 abr. 2016.

LOJKINE, Jean. A revolução informacional. São Paulo: Editora Cortez, 2002.

MELLO, Alvaro. Teletrabalho (Telework): O Trabalho em Qualquer Lugar e a Qualquer Hora. Rio de Janeiro: Qualitymark, 1999. 
PINEL, Maria de Fátima de Lima. Teletrabalhador. 2012. Disponível em: <http://www.teletrabalhador.com/index.html>. Aceso em: 30 maio 2016.

RODRIGUES, Ana Cristina Barcellos. Teletrabalho: a tecnologia transformando as relações de trabalho. 2011. 142 f. Dissertação (Mestrado em Direito) - Universidade de São Paulo (USP), São Paulo, 2011.

SCHMIDT, Marina. Modalidade de home office ganha projeção em empresas dos setores público e privado. 2016. Disponível em: <http://www.sobratt.org.br/index.php/08042016-modalidade-de-home-office-ganhaprojecao-em-empresas-dos-setores-publico-e-privado/>. Acesso em: 25 abr. 2016.

SCHROEDER, Jerusa Betina. Impactos do teletrabalho nas atividades dos docentes do Serviço Nacional de Aprendizagem Industrial (SENAI). 2007. 97 f. Dissertação (Mestrado em Administração) - Universidade Regional de Blumenau (FURB), Blumenau, 2007.

TOFFLER, Alvin A terceira onda. São Paulo: Record, 2002.

ZUFFO, João Antônio. A Sociedade e a Economia no Novo Milênio: Os empregos e as empresas no turbulento alvorecer do século xxi - Livro I - A tecnologia e a Infossociedade. São Paulo: Ed. Manole, 2004. 